\title{
Review
}

\section{The Role of Architecture and Design in the Management of Parkinson's Disease: A Systematic Review}

\author{
Joana Beisl Ramos ${ }^{\mathrm{a}, \mathrm{b}}$, Gonçalo S. Duarte ${ }^{\mathrm{a}, \mathrm{c}}$, Raquel Bouça-Machado ${ }^{\mathrm{c}, \mathrm{d}}$, Margherita Fabbri ${ }^{\mathrm{c}, \mathrm{e}}$, \\ Tiago A. Mestre ${ }^{\mathrm{f}}$, João Costa ${ }^{\mathrm{a}, \mathrm{c}}$, Tânia Beisl Ramos ${ }^{\mathrm{g}}$ and Joaquim J. Ferreira ${ }^{\mathrm{a}, \mathrm{c}, \mathrm{d}, *}$ \\ ${ }^{a}$ Laboratory of Clinical Pharmacology and Therapeutics, Faculdade de Medicina, Universidade de Lisboa, \\ Lisbon, Portugal \\ ${ }^{\mathrm{b}}$ Serviço de Anestesiologia, Centro Hospitalar Universitário Lisboa Norte, Lisbon, Portugal \\ ${ }^{\mathrm{c}}$ Instituto de Medicina Molecular João Lobo Antunes, Faculdade de Medicina, Universidade de Lisboa. \\ Avenida Professor Egas Moniz, 1649-028, Lisboa, Portugal \\ ${ }^{\mathrm{d}}$ CNS - Campus Neurológico Sénior, Torres Vedras, Portugal \\ ${ }^{\mathrm{e}}$ Department of Neuroscience Rita Levi Montalcini, University of Torino, Turin, Italy \\ ${ }^{\mathrm{f}}$ Department of Medicine, Parkinson's Disease and Movement Disorders Center, Division of Neurology, The \\ Ottawa Hospital Research Institute, University of Ottawa Brain and Mind Institute, Ottawa, Ontario, Canada \\ ${ }^{\mathrm{g}}$ Centro de Investigação em Arquitetura, Urbanismo e Design (CIAUD), Faculdade de Arquitetura, Universidade \\ de Lisboa, Lisbon, Portugal
}

Accepted 6 June 2020

\begin{abstract}
.
Background: Parkinson's disease (PD) is a neurological condition characterized by the development of daily disabling symptoms. Although the architecture and design of a PD patient's environment can hinder or facilitate full participation in daily activities, their putative role in the management of these patients has received little attention to date.

Objective: We conducted a systematic review to evaluate the evidence of architectural and design features in the management of people with PD.

Methods: An electronic database search of observational and experimental studies was conducted in MEDLINE and Embase from inception to May 2020, with two independent reviewers identifying the studies. Falls, fear of falling, postural instability, gait impairment/disability, and functional mobility were our outcomes of interest.

Results: Thirty-six studies were included, among which nineteen were observational and seventeen were experimental studies (overall participants $=2,965$ ). Pavement characteristics, notably unstable surfaces and level differences, were found to be a major cause of falling. Ground-based obstacles and confined/narrowed spaces were found to disturb gait, increase postural instability, and decrease functional mobility. Housing type did not appear to increase risk of falling, nor to significantly explain concerns about falling.

Conclusion: Findings suggest a need to adjust architectural features of the surrounding space to ensure appropriate care and provide a safe environment to PD patients. More evidence about the impact of such modifications on PD outcomes is needed.
\end{abstract}

Keywords: Parkinson's disease, architecture, design, systematic review, qualitative evidence synthesis

${ }^{*}$ Corresponding authors. Prof. Joaquim J. Ferreira, MD, $\mathrm{PhD}$, Laboratório de Farmacologia Clínica e Terapêutica, Faculdade de Medicina de Lisboa, Av. Prof. Egas Moniz,
1649-028 Lisboa, Portugal. Tel.: +351 21 7802120; E-mail:

jferreira@medicina.ulisboa.pt. 


\section{INTRODUCTION}

Parkinson's disease (PD) is a chronic progressive neurodegenerative disorder affecting about $1 \%$ of people over the age of 60 , with a prevalence as high as $4 \%$ in older populations [1]. As a reflection of increased life expectancy and other factors, the number of individuals living with this condition is expected to increase considerably over the next decades [2-4], with the prevalence likely to double by the year 2030 among people over the age of 50 [3]. Therefore, the burden of this disease on patients, caregivers, and healthcare systems will rise, representing a growing challenge to society [4].

PD is characterized by the development of disabling motor and non-motor symptoms over time [5-7]. For instance, progressive loss of postural reflexes leads to balance impairments and gait disturbances, common features among these patients that are found to be associated with increased risk of falls and injury, decreased mobility, and reduced quality of life and survival $[6,8-10]$. Indeed, nearly half of people with PD regularly experience freezing of gait (FOG), reaching about $80 \%$ of the people severely affected [11].

Evidence suggests that these clinical impairments promote difficulty walking in real-world environments, either at home or in the community [12-15]. Additionally, such disabilities are often affected by constraints in the physical environment. This is particularly true for FOG, commonly experienced during step initiation, but also when approaching a destination, facing obstacles or distractions, and in stressful situations [16].

It is accepted that the design and features of the physical environment can hinder or facilitate full participation in activities for people living with PD. Therefore, architecture may play a role in the management of PD patients, being relevant when planning, designing, and constructing physical structures, encompassing both housing and urban spaces. For instance, architectural features of the built environment are acknowledged to be essential for independence and health outcomes of older people [17] and some patients with neurodisabilities, such as those resulting from dementia [18-25] and stroke [26, 27]. However, this line of inquiry has been largely neglected in people with PD, with only $9 \%$ of patients being referred to therapists specialized in home environment risk assessments [28, 29].
This systematic review aims to evaluate the knowledge about architectural and design features with potential implications in the management of PD, concerning both health outcomes and functional mobility.

\section{MATERIALS AND METHODS}

We conducted a systematic review of observational and experimental studies that measured the impact of architectural and design features of the physical environment on PD-related clinical outcomes. We assessed fall-related outcomes (postural instability, falls, and fear of falling), gait impairments/disability (FOG, motor blocks, and gait parameters), and functional mobility (housing accessibility and usability and mobility disability).

For the purpose of this review, we defined efficacy measures related to architecture and design features as any environmental or person-focused feature that involves physical modifications of the built environment with the goal of enhancing the performance of activities of daily living among people with PD. Definitions of such measures are provided in Table 1.

\section{Literature search}

We searched MEDLINE and Embase from inception to May 2020, using the electronic search strategy presented in the Supplementary Table 1.

\section{Study selection}

We included observational studies (case-control, cross-sectional, and prospective cohort) and experimental studies that evaluated architectural or design features of the built environment and its impact on PD outcomes across any setting (community, rehabilitation, acute care, and long-term care).

Studies were excluded when no specific details of architectural and design features of the environment were provided and when the study population was other than people diagnosed with idiopathic PD. Additionally, narrative reviews, study protocols, abstracts, and conference proceedings were excluded. Only English-language studies were included.

Two reviewers (JBR and GD) independently screened the titles and abstracts identified from searches. Any paper identified as potentially relevant by at least one review author was retrieved. Two reviewers (JBR and GD) independently screened full-text articles, with discrepancies resolved by dis- 
Table 1

Parkinson's disease related architecture/design efficacy measures [85-87]

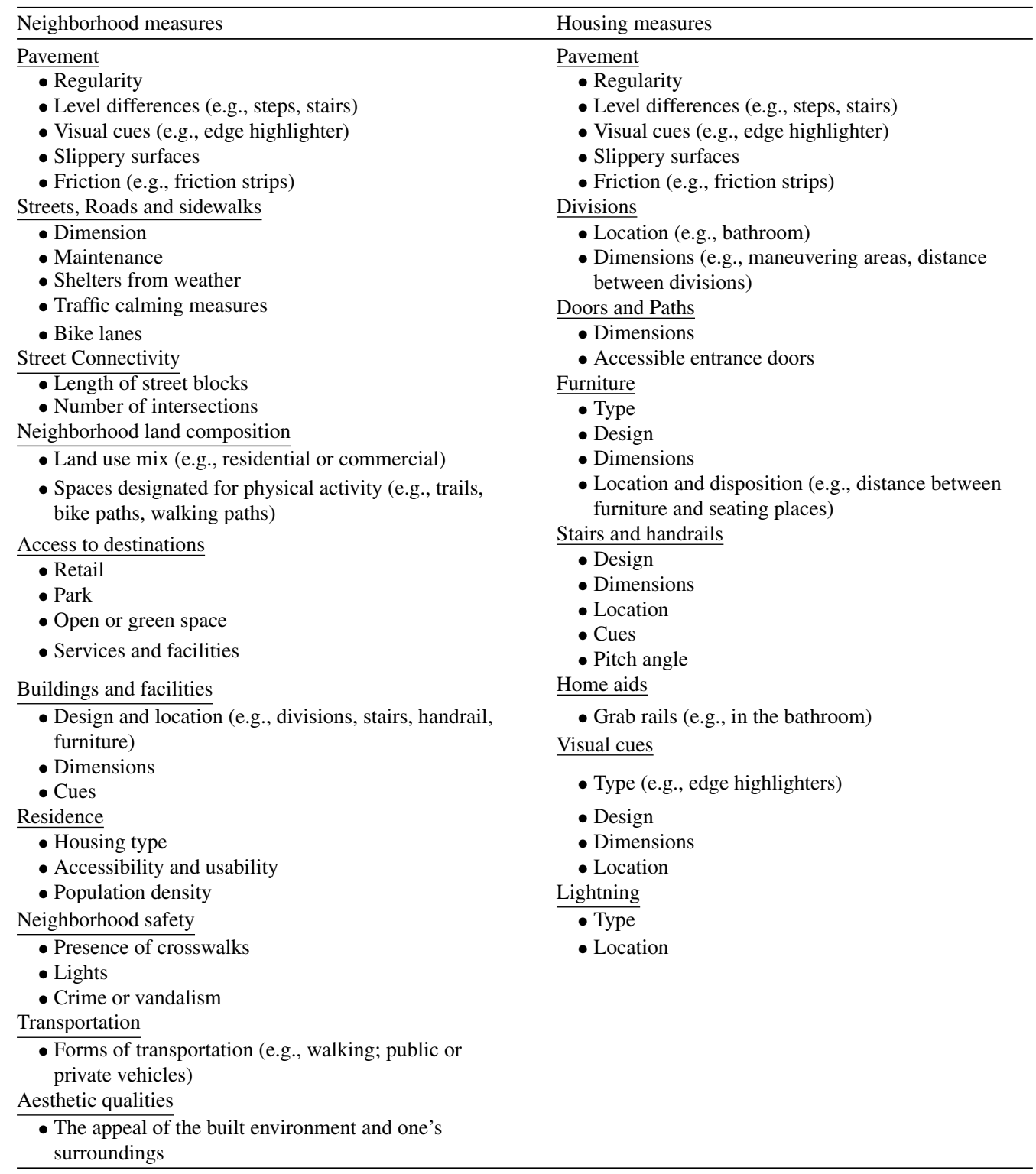

cussion. The references of relevant studies were cross-checked for additional studies not identified by the electronic search.

\section{Data extraction}

We extracted information including the study characteristics (publication year, study period, study design), participant characteristics (number, age, sex, disease duration, PD-related impairment, and rel- evant treatment information), in addition to other disease specific-characteristics of interest.

\section{RESULTS}

The electronic search yielded a total of 4,190 citations. After screening, 36 studies were included in the present review. The flow chart is presented in Fig. 1.

We included 19 observational studies, namely case-control $(n=1)$, prospective cohort $(n=4)$, and 


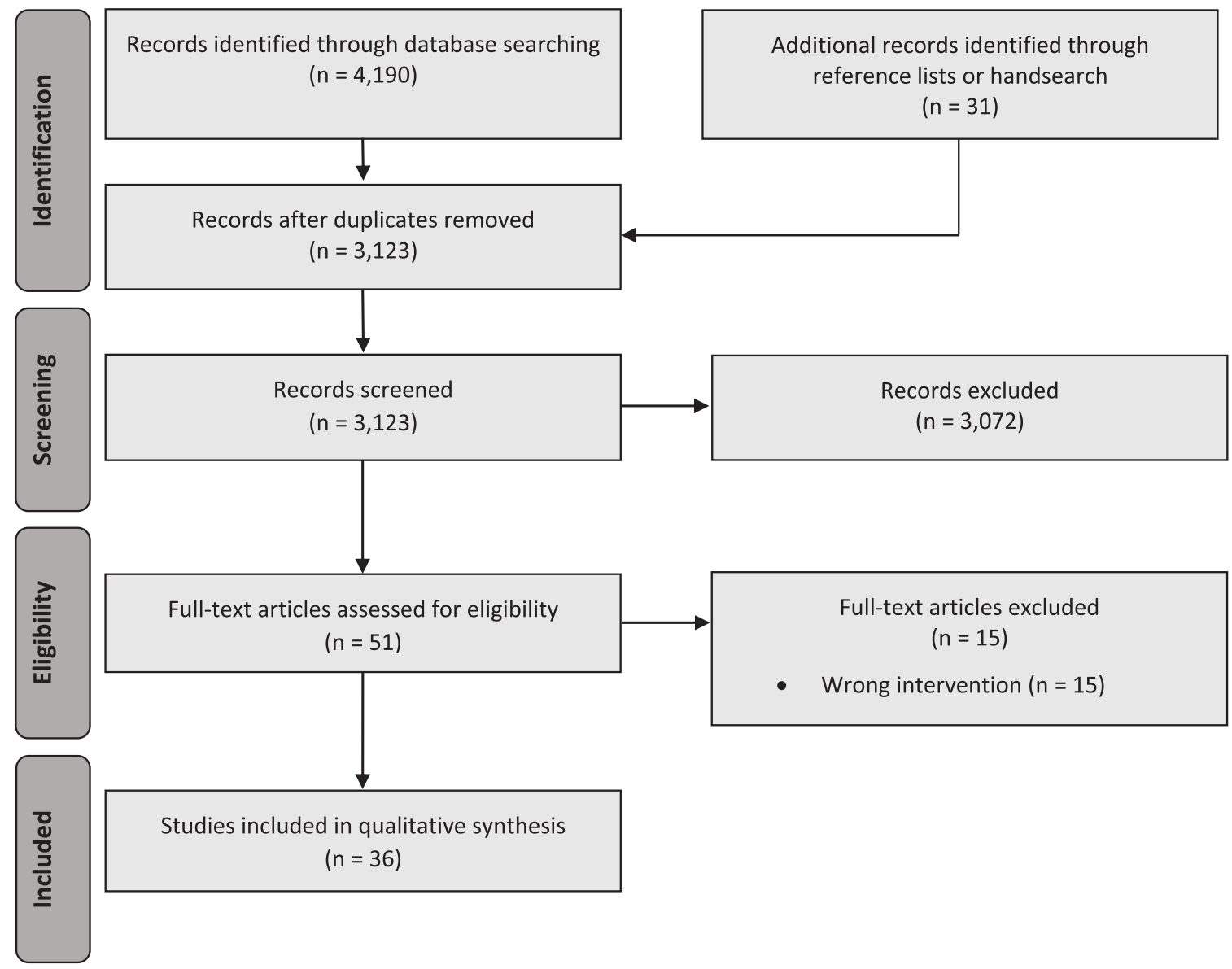

Fig. 1. PRISMA flow diagram [88].

cross-sectional $(n=14)$ designs. All other studies were experimental in design $(n=17)$, although no randomized trial was found. Overall, 2,965 people with PD were enrolled (range: 1 to 990 participants). The characteristics of these studies can be seen in the Supplementary Table 2.

In terms of PD-related outcomes, fall-related outcomes $(n=12)$ and gait impairments/disability $(n=21)$ were the most frequently reported outcomes, followed by functional mobility $(n=6)$. No study reported mortality or costs, and no other outcomes were found. The architectural features assessed and the respective PD outcomes measured are detailed below and summarized in Table 2 .

Because of the heterogeneity of the included studies and variability of the outcomes reported a meta-analysis was not performed. A qualitative synthesis was made based on the most frequently reported results. The most significant results are illustrated in Fig. 2.

\section{Fall-related outcomes}

Pavement characteristics were the most commonly assessed architectural features of the built environment $(n=11)$, followed by confined spaces $(n=3)$, and housing type $(n=2)$.

Seven articles reported falling [30-36], four studies reported fear of falling [37-40], and one study reported postural instability [13] as outcomes. Among these, nine studies were observational, namely cross-sectional $(n=6)$ [30, 34, 35, 37-40] and prospective cohort $(n=3)$ [31, 32, 36] designs, and two studies used an experimental design $(n=2)$ $[13,33]$.

To survey the circumstances surrounding falls, Stack et al. [30, 34] developed two cross-sectional design studies where questionnaires were used, and found trip hazards to be the main driver of sudden falls or near falling, namely uneven pavements, curbs, steps, skirting boards, doorways, and carpets. In addi- 
Table 2

Parkinson's disease outcomes and architectural/design features in selected studies

\begin{tabular}{|c|c|c|c|c|c|c|}
\hline & \multicolumn{5}{|c|}{ Outcome measures } & \\
\hline & \multicolumn{3}{|c|}{ Fall-related outcomes } & \multirow[t]{2}{*}{ Gait } & \multirow[t]{2}{*}{ Functional Mobility } & \\
\hline & $\begin{array}{l}\text { Postural } \\
\text { instability }\end{array}$ & Falls & Fear of falling & & & \\
\hline Almeida et al. 2005 [57]; 2010 [46] & & & & Doorways/Lights & & \\
\hline Ashburn et al. 2008 [32] & & $\begin{array}{l}\text { Floor surface/Stair } \\
\text { rails/Height of shelves }\end{array}$ & & & & \\
\hline Cole et al. 2011 [33] & & Floor surface & & Floor surface & & \\
\hline Cowie et al. 2010 [47]; 2011 [49] & & & & Doorways & & \\
\hline Ehgoetz et al. 2013 [56] & & & & $\begin{array}{l}\text { Doorways/Confined } \\
\text { spaces/Open } \\
\text { space/Lights }\end{array}$ & & \\
\hline Gál et al. 2019 [58] & & & & Floor surface & & \\
\hline Galna, et al. 2013 [13] & Obstacle course & & & & & \\
\hline Gazibara et al. 2014 [35]; 2016 [36] & & Floor surface/Obstacle & & & & \\
\hline Giladi et al. 1992 [41] & & & & Narrow spaces & & \\
\hline Gray et al. $2000[31]$ & & $\begin{array}{l}\text { Floor sur- } \\
\text { face/Stairs/Confined } \\
\text { spaces/Housing type }\end{array}$ & & & & \\
\hline Haak et al. 2013 [63] & & & & & Housing adaptations & \\
\hline Jonasson et al. 2015 [40] & & & Housing type & & & \\
\hline Jones et al. 2008 [37] & & & $\begin{array}{l}\text { Confined spaces/Steps/ } \\
\text { stairs }\end{array}$ & $\begin{array}{l}\text { Floor sur- } \\
\text { face/Stairs/Doorways/ } \\
\text { Furniture/Bath }\end{array}$ & & \\
\hline $\begin{array}{l}\text { Kataoka et al. } 2011 \text { [50]; } 2012 \text { [54]; } \\
2018 \text { [55] }\end{array}$ & & & & $\begin{array}{l}\text { Narrow spaces/Confined } \\
\text { spaces }\end{array}$ & & \\
\hline Lamont et al. 2012 [60] & & & & & $\begin{array}{l}\text { Floor } \\
\text { surface/Lights/Signaled } \\
\text { pedestrian crossings }\end{array}$ & 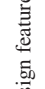 \\
\hline Lebold et al. 2010 [48] & & & & Doorways & & $\frac{5}{20}$ \\
\hline Lee et al. 1999 [42] & & & & Narrow spaces & $\begin{array}{l}\text { Reaching/Space between } \\
\text { objects }\end{array}$ & 胥 \\
\hline Mak et al. 2013 [53] & & & & Traffic lights signals & & $\stackrel{\mathscr{g}}{\overparen{E}}$ \\
\hline $\begin{array}{l}\text { Nieuwboer et al. } 2001 \text { [43]; } 2004 \\
\text { [45] }\end{array}$ & & & & $\begin{array}{l}\text { Narrow spaces/Obstacle } \\
\text { course }\end{array}$ & & 离 \\
\hline Nilsson et al. 2012 [39]; 2013 [61] & & & Stairs & & $\begin{array}{l}\text { Housing accessibility and } \\
\text { usability }\end{array}$ & \\
\hline Oates et al. 2013 [52] & & & & Floor surface & & \\
\hline Pretzer-Aboff et al. 2009 [59] & & & & & $\begin{array}{l}\text { Safety bars/Shower } \\
\text { benches/Lift chairs/Height } \\
\text { of objects/Confined } \\
\text { spaces/Stairs }\end{array}$ & \\
\hline Rahman et al. 2008 [16]; 2011 [38] & & & $\begin{array}{l}\text { Floor surface/Stairs/ } \\
\text { Reaching }\end{array}$ & $\begin{array}{l}\text { Floor } \\
\text { surface/Stairs/Narrow } \\
\text { spaces/Confined } \\
\text { spaces/Doorways/Door } \\
\text { handles/Lights/Street } \\
\text { roads }\end{array}$ & & \\
\hline Schaafsma et al. 2003 [44] & & & & Narrow spaces & & \\
\hline Slaug et al. 2013 [62] & & & & & Housing accessibility & \\
\hline Stack et al. 1999 [30]; 2013 [34] & & $\begin{array}{l}\text { Floor sur- } \\
\text { face/Steps/Confined } \\
\text { spaces/Doorways }\end{array}$ & & & & \\
\hline Stegemöller et al. 2012 [51] & & & & Obstacle course & & \\
\hline
\end{tabular}




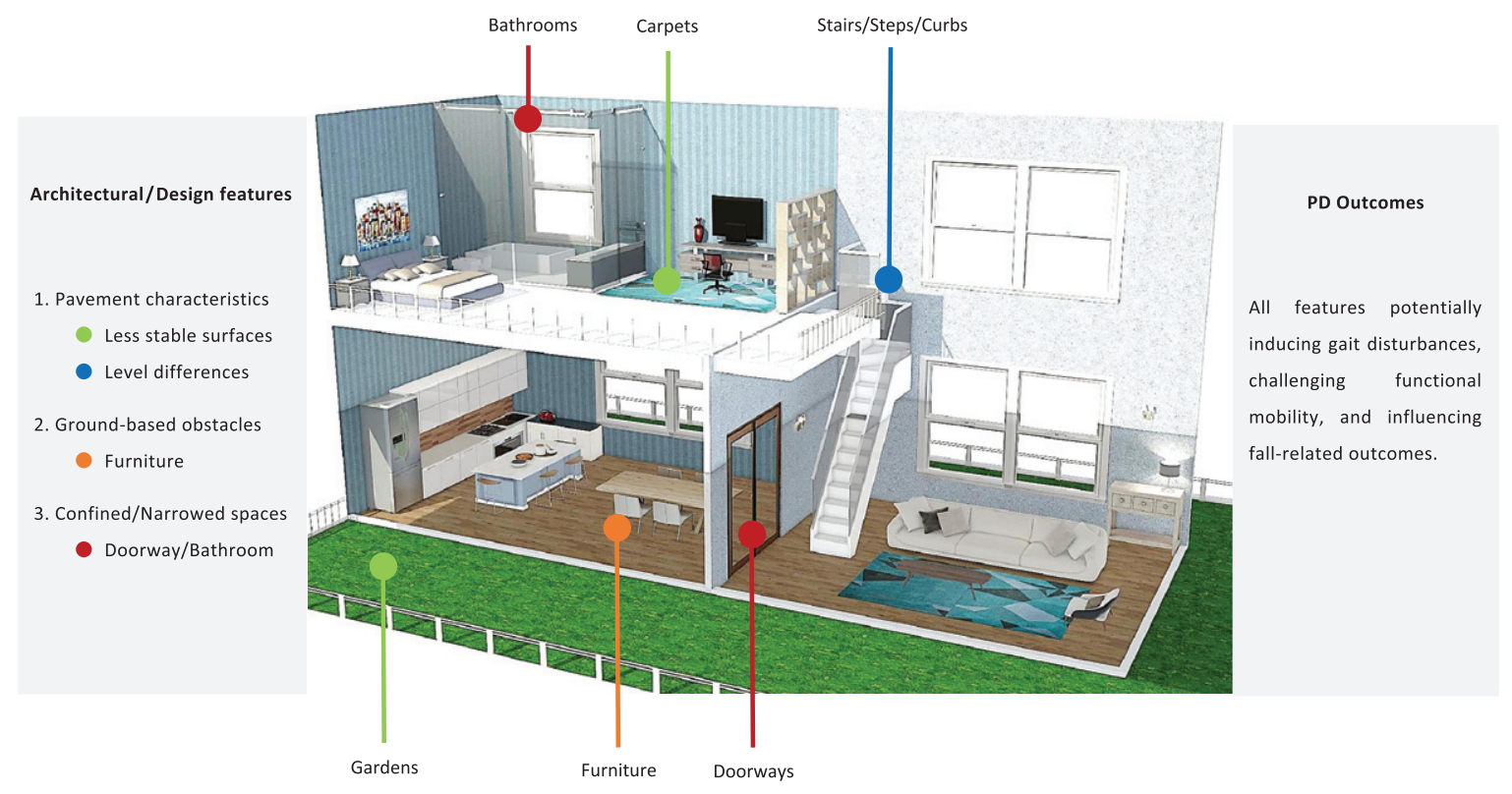

Fig. 2. Architectural plan with a summary of the most significant architectural/design features of the built environment. Homestyler online software was used. PD, Parkinson's disease.

tion, steps and doorways were reported to be the primary locations of such events within the home. Similarly, in a prospective-cohort study where fall diaries were used to assess fall related characteristics, Gray et al. [31] found carpets to be the most common location of falls, referring further confined spaces to be also important fall locations. However, neither the use of stairs nor the housing type was found to increase the risk of falling.

Additionally, research has been conducted on where falls occur (outdoors versus indoors). In a cross-sectional study where interviews were conducted, Gazibara et al. [35] found a small though statistically significantly higher frequency of outdoor falls compared with indoor falls among persons with $\mathrm{PD}$, although a prospective cohort study conducted by the same authors found indoor falls to be more common than outdoor falls [36]. In both studies, outdoor falls were mostly preceded by extrinsic factors, notably slipping and tripping while walking over a curb or an object on the ground, such as a carpet. Moreover, in a prospective cohort study developed by Ashburn et al. [32] where fall diaries were recorded, $80 \%$ of falls were found to happen at home, mostly in bedrooms, living rooms, and kitchens, with tripping during walking being the biggest single cause of falls. Additionally, more falls happened outdoors in gardens than in the bathroom, hallway, or on the stairs, a finding that was attributed to challenges posed by uneven surfaces, unanticipated trip hazards, and difficult maneuvers. Furthermore, Cole et al. [33], in an experimental study where gait was assessed while walking on two different surfaces (firm and foam surfaces), also suggested an increased risk of tripping and falling on less stable surfaces, particularly on compliant or uneven surfaces, where the height of the walking surface is not uniform.

Four studies reported findings regarding fear of falling, all using a cross-sectional design. For instance, through semi-structured interviews Jones et al. [37] found that turning in confined spaces, steps, and stairs universally increased the fear of falling, whether outside or around the home. In addition, by collecting data by a postal survey, Nilsson et al. [39] found walking difficulties to be the strongest factor contributing to fear of falling, among which climbing stairs seemed to be of particular importance. However, one study by Jonasson et al. [40] suggested that housing type and residential area have no significant impact on people's fear of falling, despite suggesting that these factors remain a concern. Finally, Rahman et al. [38] recognized, through the use of several scales, that some activities are actively avoided by PD patients due to fear of falling, such as going outside in slippery conditions, going to crowded places, going up and down stairs, taking a shower, and either reaching for something above head level or bending down. 
Galna et al. [13] was the only study to report findings related to postural instability. This experimental study performed a center of mass analysis during gait, suggesting that environmental hazards, such as ground-based obstacles, may accentuate postural instability and the subjective impression of near falls in people with PD.

\section{Gait impairment}

Twenty-one articles reported gait as an outcome [16, 33, 48-57, 37, 58, 41-47], mostly concerning FOG. Among these, five studies were observational, namely case-control $(n=1)$ [41], cross-sectional $(n=3)[16,37,42]$, and prospective cohort $(n=1)$ [55] designs, and sixteen studies used an experimental design $(n=16)$ [33, 43, 52-54, 56-58, 44-51].

Lee et al. [42] conducted a cross-sectional study using questionnaires, and found that $70 \%$ of participants had problems moving through confined or narrow spaces (e.g., doorways) within the home, predominantly due to bumping and FOG (78\% overall). Rahman et al. [16] also conducted a cross-sectional study and, through the use of questionnaires, recognized other factors that potentially induce FOG, namely bright lights and crossing roads. On the other hand, climbing stairs was found to improve walking and overcome FOG. In addition, Jones et al. [37] used semi-structured interviews to examine perceived walking challenges. Busy outdoor environments were reported to pose unpredictable challenges, while in indoor environments doorways were specifically a major trigger for FOG. Furthermore, furniture was found to challenge gait, especially for people with higher Unified Parkinson's Disease Rating Scale and FOG Questionnaire scores. Both studies identified attentional and external cueing strategies that helped improve gait, such as following lines on the floor, walking over tile edges or paving stones, looking at pavement cracks, and using a strip across a door threshold [16, 37].

Additional research was undertaken regarding confined or narrow spaces. For instance, Giladi et al. [41] assessed 990 PD patients in a case-control study and found narrow spaces (e.g., doorways) to be the cause of motor blocks in $25 \%$ of cases. Later, Nieuwboer et al. published two articles [43, 45] using an experimental design where gait was assessed under three conditions (normal, stop, or block/freezing conditions), and proposed that in people with PD the confrontation with visual stimuli suggesting a limited space (e.g., narrow walkway) or a change of direction (e.g., obstacle course) can potentially induce FOG. Additionally, Schaafsma et al. [44] also conducted an experimental study in a gait laboratory, finding FOG to be elicited by walking in narrow spaces, particularly during "off" states.

Later, Almeida et al. [46] and Lebold et al. [48] developed two experimental studies aiming to assess gait under three doorway conditions, namely narrow, normal, and wide. They suggested that narrow doorways may result in gait differences between PD individuals and healthy controls, finding that the narrow doorway condition was significantly associated with gait changes and FOG experienced among the participants. In addition, Cowie et al. [47, 49] developed two experimental studies where gait kinematics were measured under four doorway conditions: no door, narrow door, medium door, and wide door widths. They identified abnormal walking responses to doorways in PD patients who regularly experience FOG, with disturbances becoming more pronounced as door width decreases $(p<0.001)$. Furthermore, Kataoka et al. [50, 54] assessed gait patterns in a suddenly narrowed path and confined spaces, and showed that the moments preceding these were characterized by gait variability in patients with Hoehn-Yahr stage III PD. More recently, another study developed by Kataoka et al. [55] prospectively studied 26 patients with Hoehn-Yahr stage III PD for six years, aiming to evaluate the disease progression and to analyse gait parameters under two circumstances: a suddenly narrowed path and a straightly narrowed path. They found an increase in the number of steps associated with FOG when walking on narrowed paths, particularly on a path that narrows suddenly.

Additionally, Ehgoetz et al. [56] developed an experimental study aiming to evaluate gait in the dark under five doorway conditions, namely walking through a doorway to a confined space in complete darkness, with door frame illuminated, or with both the door and limbs illuminated, and walking away from the doorway into an open space in complete darkness or with limbs illuminated. FOG occurrences were found to be four times more often when walking toward a standard doorway to a confined space, than walking away from the doorway into a large open space. In addition, illuminating the door frame was found to reduce FOG by $38 \%$ compared to walking through the door in complete darkness. Additional experimental research was developed by Almeida et al. [57], who assessed gait in complete darkness in comparison to a regularly lighted room, suggesting that individu- 
als with PD adapt walking in the dark presumably to optimize safety.

Stegemöller et al. [51] evaluated gait kinematics in an experimental study and under two circumstances (normal walking and obstacle crossing), and found that decreased walking ability was present when an obstacle needed to be overcome. In addition, Cole et al. [33] and Oates et al. [52] conducted experimental studies to assess gait while walking on different surfaces, such as firm, soft, and slippery surfaces. They found that people who fell adapt differently to walking on unstable surfaces than age-matched controls, and that PD patients may alter their gait kinetic when walking on a slippery surface. Recently, an experimental study developed by Gál et al. [58] assessed gait under six floor patterns, with the reference pattern being a virtual large transverse chessboard, and the other patterns differing either in size (small floor stones), orientation (diagonal), nature (real paving), regularity (irregular), or no pattern. They observed no direct effect on FOG in overall and no differences in gait parameters between large and small floor stones. Additionally, they found improvement in gait parameters when walking on large, virtual, regular, transverse chessboard floor stones, compared with walking on no pattern or on real, irregular or diagonal floor stones.

Finally, Mak et al. [53] reported gait performance parameters under three different conditions (walking at a natural pace, and either walking while doing a cognitive task with or without the addition of traffic lights). In this study, PD patients when exposed to traffic lights experienced benefits in terms of stride length, cadence, and gait velocity $(p<0.001)$.

\section{Functional mobility}

Six studies reported functional mobility outcomes [42, 59-63], mostly regarding housing accessibility and housing adaptations. All studies were crosssectional.

Pretzer-Aboff et al. [59] explored the facilitators and barriers encountered by PD patients and caregivers to optimize participation in functional activities and exercise. The home environment, particularly small places, clutter, and stairs, was reported to challenge the functional mobility of people with PD. Additionally, environmental interventions, such as the use of safety bars, shower benches, lift chairs, and raised beds and seats, were described as fostering independence, sense of security and safety, and improving mobility among the participants.
Further, a study by Lamont et al. [60] sought to understand the facilitators and barriers to walking in the community perceived by people with PD and their partners through the use of focus groups. Environmental factors were identified as the main barriers to community walking, including crowded environments, pavement characteristics, bad weather, and reduced or fluctuating lighting. Only one aspect of the physical environment, i.e., signaled pedestrian crossings, was described as a facilitator to community walking.

Nilsson et al. [61] and Slaug et al. [62], using structured interviews, housing observation and selfratings, and a version of the Housing Enabler Instrument, found that elderly people with selfreported PD have more accessibility problems with their housing and experience less usability of their home than the elderly in general. In addition, elderly people with self-reported PD were also found to be less independent in activities of daily living, to have more functional limitations and to be more dependent on walking aids [61]. Although the number of environmental barriers did not differ between the studied populations, the top 10 environmental barriers that generated the most accessibility problems in PD individuals were identified, and include, among others: wall-mounted cupboards and shelves placed extremely high in the kitchen; few or no seating places in the outside spaces; lack of grab bars in the shower, bath, or toilet; high curbs outdoors; uneven surfaces outdoors; and bathtubs [62]. Moreover, misjudging the space between objects and problems reaching for objects were also problems reported by Lee et al. [42] Finally, Haak et al. [63] used structured interviews to identify the hygiene area as the most common location where PD individuals used housing adaptations.

\section{DISCUSSION}

To our knowledge, this is the first systematic review evaluating the potential role of architecture and design in the management of people with PD. Less than half of the pre-specified architecture and design measures were assessed in the included studies, with pavement characteristics being the most frequently mentioned $(n=21)$. For instance, walking on less stable surfaces (e.g., carpets, gardens) or on surfaces with level differences (e.g., skirting boards, steps, stairs, curbs) were found to be the major context of falls among PD patients [30-36]. Additionally, walking difficulties in daily life situations were the 
factors that most contributed to fear of falling [39, 40], among which climbing steps, stairs and slippery surfaces were suggested as particularly important [37-39, 59]. However, the results concerning climbing stairs are inconsistent, with one study not linking them to an increased risk of falling [31] and other study suggesting a beneficial effect on FOG [16]. In fact, gait improvement during staircase negotiation has already been observed in PD patients [64-66], with the lines of the steps appearing to act as cues to maintain the flow of gait [67].

Because pavement characteristics have been implicated several times in the risk of falling, fear of falling and gait disturbances, it should be one of the main intervention areas for people with PD. For instance, it was recently suggested that $P D$ patients may benefit from floor patterns incorporating transverse oriented large rectangular visual cues [58], although no further details on floor adaptations were obtained. In addition, visual and auditory cueing techniques, e.g., transverse lines on the walkway, have been used as an effective component of locomotor therapy for people with PD [68-71] and are recommended at Hoehn-Yahr stage II [72]. However, further research is needed to provide evidence of their effectiveness to ameliorate gait in a home setting [73-75], as they must be provided in a person-specific and practical manner outside the laboratory $[67,72,75,76]$. For example, although people with PD may be particularly dependent on visual feedback to compensate their motor deficits [77, 78], ophthalmologic symptoms developed in the course of the disease, e.g., impaired night vision, frequently interfere with daily activities in PD and should be carefully considered [77-79].

Furthermore, a recent review suggested that standard architecture may not be optimized for the elderly, namely regarding the stable and safe use of stairs, which was found to require shorter heights and longer tread lengths, as older adults appear to negotiate stairs with reduced stability, with increased tolerance at a lower stair height, and therefore a greater risk for falling [80]. This is particularly true in PD patients, as they generate less potent lifting forces, and rely more on the hip joint during a single-step ascent [81]. Installing visual cues and adjusting size, structure or shape of the handrails are common recommendations on environmental adaptations for people with PD $[67,76]$. However, although handrails were suggested to reduce trip hazards among PD patients [32], more specific details on an optimal design were not obtained in any of the included studies. In addition, the value of handrails in preventing falls has also been investigated in the general population, with findings leading to recommendations concerning design and location [82]. Specifically, depth of the finger space on the sides of handrails was found to positively affect handrail performance by facilitating protective grasping, whereas the width of the handrail and the height of the handrail crown were shown to be irrelevant for handrail performance [82].

Ground-based obstacles were reported to challenge the functional mobility of people with PD $[37,51,59]$, potentially by inducing FOG $[43,45]$ and by accentuating postural instability [13]. Therefore, because the ability to negotiate obstacles in the environment is necessary for overall mobility and independent living, environmental adaptations were suggested in order to reduce trip hazards, namely removing obstructions in walkways [32]. However, no study provided specific details regarding the adjustment of furniture dimension or disposition. Despite this, recommendations on such environmental adaptations for people with PD already exist, and include both the removal of obstacles and the rearrangement of space and furniture with attention to ergonomics $[67,76]$.

Additionally, confined and narrowed spaces within the home were also found to challenge PD individuals' functional mobility $[59,62]$, potentially inducing gait disturbances $[16,37,41-45,54-56]$ and increasing the risk of falling $[30,31,34]$. For instance, doorways were found to be a major FOG trigger [37], whose risk appears to be more pronounced as door width decreases [46, 47, 49]. Accordingly, housing adaptations were proposed, including ensuring that bathrooms have enough space so that PD patients do not feel obstructed in a restricted environment [29]. However, despite being easily modified, narrow doorways and confined spaces remain particularly associated with gait disturbances and, for that reason, a potential area of intervention.

Lighting conditions were also considered $[16,56$, $57,60]$, with results suggesting that inadequate light induce gait disturbances in PD individuals. Similarly, such conditions have also been addressed in the elderly population and in people with neurodisabilities other than PD. Among older adults, sufficient ambient light was suggested to improve performance during stair negotiation, while reduced light conditions were found to increase the risk of tripping [80]. Concerning people with dementia, environmental cues, notably lighting and furniture layout, were suggested to support their spatial orientation and 
Table 3

Summary of potential architectural/design adaptations in the management of PD

\begin{tabular}{|c|c|c|c|c|c|c|c|c|}
\hline & & \multicolumn{5}{|c|}{ Outcome measures } & \multicolumn{2}{|c|}{ Architectural/design adaptations } \\
\hline & & \multicolumn{3}{|c|}{ Fall-related outcomes } & \multirow[t]{2}{*}{ Gait } & \multirow{2}{*}{$\begin{array}{l}\text { Functional } \\
\text { Mobility }\end{array}$} & \multirow[t]{2}{*}{ Suggested in the included studies } & \multirow[t]{2}{*}{ Authors' advice* } \\
\hline & & $\begin{array}{l}\text { Postural } \\
\text { instability }\end{array}$ & Falls & $\begin{array}{l}\text { Fear of } \\
\text { falling }\end{array}$ & & & & \\
\hline \multirow{12}{*}{ 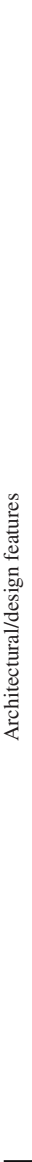 } & - Level differences & - & Yes & Yes & Yes & Yes & $\begin{array}{l}\text { Adding stair rails to reduce trip hazards } \\
\text { [32]. }\end{array}$ & $\begin{array}{l}\text { Consider removing irregular or less stable } \\
\text { surfaces (e.g., carpets, rugs, mats); Assess } \\
\text { the need for stair rails adjustments (e.g., } \\
\text { extra banister rails and spiral [Newell } \\
\text { post] rails for corners on stairs; adaptation } \\
\text { of size and shape of handrails to enable } \\
\text { better grip). }\end{array}$ \\
\hline & $\begin{array}{l}\text { Ground-based obstacles } \\
\text { • Furniture/obstacle course }\end{array}$ & Yes & Yes & - & Yes & - & $\begin{array}{l}\text { Home environment clearance (ground } \\
\text { clearance) }[16,32,37] .\end{array}$ & $\begin{array}{l}\text { Rearrange space and objects to create an } \\
\text { unobstructed walking route. }\end{array}$ \\
\hline & Spaces dimensions & & & & & & & \\
\hline & - Confined/narrowed spaces & - & Yes & Yes & Yes & Yes & $\begin{array}{l}\text { Removing narrowed entrances to prevent } \\
\text { gait instability [54]. }\end{array}$ & $\begin{array}{l}\text { Consider removing narrow spaces and } \\
\text { expanding doors; Consider the use of } \\
\text { handrails down corridors to increase gait } \\
\text { confidence. }\end{array}$ \\
\hline & Residence & & & & & & & \\
\hline & - Housing type & - & Yes & Yes & - & - & NA & $\mathrm{X}$ \\
\hline & - Accessibility and usability & - & Yes & - & Yes & Yes & $\begin{array}{l}\text { Altering the high of the shelves to reduce } \\
\text { reaching falls [32]; Targeting accessibility } \\
\text { barriers to decrease functional limitations } \\
\text { [62]. }\end{array}$ & $\begin{array}{l}\text { Ensure ergonomic sizes and proper support } \\
\text { from furniture and home aids. }\end{array}$ \\
\hline & - Home aids & - & - & - & Yes & Yes & $\begin{array}{l}\text { Using visual cues (following lines on the } \\
\text { floor) to improve gait [16]; Using visual } \\
\text { light cues to facilitate balance control } \\
\text { [52] and gait [56]; Using adaptive devices } \\
\text { (safety bars, shower benches, lift chairs, } \\
\text { raised beds and seats) to foster } \\
\text { independence and promote mobility [59]. }\end{array}$ & $\begin{array}{l}\text { Assess the need for additional lighting } \\
\text { (e.g., automatic night-lights; good } \\
\text { lighting on stairs and on route to the } \\
\text { bathroom); Provide as needed grab rails } \\
\text { (e.g., by the toilet, bath/shower, steps or } \\
\text { bed) and shower benches. }\end{array}$ \\
\hline & Neighborhood safety & & & & & & & \\
\hline & - Lights & - & - & - & Yes & Yes & NA & $\begin{array}{l}\text { Install good lighting and sufficient visual } \\
\text { contrasts. }\end{array}$ \\
\hline & - Signaled pedestrian crossings & - & - & - & - & Yes & $\begin{array}{l}\text { Using signaled pedestrian crossings to } \\
\text { facilitate community walking [60]. }\end{array}$ & $X$ \\
\hline & - Traffic lights signals & - & - & - & Yes & - & $\begin{array}{l}\text { Using traffic lights as preparatory and } \\
\text { ongoing audiovisual cues to improve gait } \\
\text { parameters [53]. }\end{array}$ & $\mathrm{X}$ \\
\hline
\end{tabular}

Abbreviations: -, Not measured; NA, Not applied; X, Conflicting results or more robust evidence is missing. *Authors' advice based on scientific evidence combined with clinical expertise. In agreement with European Guidelines for Physiotherapy and Occupational therapy in PD $[67,72,76]$.

wayfinding [23]. In the management of PD, such environmental adaptations are also recommended and include installing good lighting and sufficient visual contrasts and assessing the need for additional lighting, e.g., automatic night-lights $[67,76]$.

Finally, housing type and residential area did not significantly explain concerns about falling in people with PD, neither housing type was associated to an increased risk of falling [31, 40]. However, some features of the residential area were identified as barriers to walking in the community among these patients, including uneven or less stable pavements, inappropriate lighting, and crowded environments $[37,60]$.
This finding is also observed in the elderly population, where factors such as residential density and vacancy rate were found to be negatively associated with physical activity [83]. It is noteworthy that, although crossing roads were suggested to induce FOG [16], signaled pedestrian crossings were found to act as a facilitator to community walking among people with PD [60]. In addition, the provision of traffic lights as audio-visual cues was found to significantly improve walking performance in PD [53], although such cues may be either misinterpreted by pedestrians or absent in many traffic intersections, resembling what happens with the blind [84]. 
Despite the research, there is limited evidence assessing the impact of architectural modifications designed specifically for the management of people with PD. For instance, housing accessibility and usability were studied in relation to how they are adapted to a living environment, identifying barriers and facilitators, but without providing robust evidence regarding the measures to be taken. In addition, there are conflicting results regarding the most common fall location (indoor versus outdoor) among people with PD that merit further study $[32,35,36]$.

\section{Limitations}

Our study has several limitations. For instance, by restricting our inclusion criteria to English-language studies, we may have missed relevant data from other sources. Additionally, data accuracy may have been limited because of recall bias, as well as omissions of outcomes and sample characteristics. For example, many results were based on PD patients' subjective perceptions of events and risk situations, thus being more prone to recall bias. Wearable technologies that are able to continuously monitor PD patients may be used in future studies to reduce such subjective elements.

Another potential limitation is that some patient characteristics, such as age, PD-specific disability, and outcome definitions across studies, were variable, meaning that caution must be exercised when pooling the findings. We suggest the creation of a standardized questionnaire, ideally elaborated by a multidisciplinary team, including physicians, nurses, psychologists, architects, and designers, to assess the impact of architecture and design on patients mobility and quality of life.

In conclusion, we found evidence that some elements of the built environment may have a role in fall-related outcomes, gait disturbances, and functional mobility in people with PD. However, the available evidence regarding the impact of personand context-specific interventions remains sparse. A summary of potential architectural/design adaptations in the management of $\mathrm{PD}$ is presented in Table 3.

\section{ACKNOWLEDGMENTS}

This study was not supported by any direct or indirect governmental or non-governmental funding. Material support was provided by the Laboratory of Clinical Pharmacology and Therapeutics, Faculty of Medicine, University of Lisbon.

\section{CONFLICT OF INTEREST}

The authors have no conflict of interest to report.

\section{SUPPLEMENTARY MATERIAL}

The supplementary material is available in the electronic version of this article: https:// dx.doi.org/10.3233/JPD-202035.

\section{REFERENCES}

[1] de Lau LML, Breteler MMB (2006) Epidemiology of Parkinson's disease. Lancet Neurol 5, 525-535.

[2] GBD 2015 Neurological Disorders Collaborator Group (2017) Global, regional, and national burden of neurological disorders during 1990-2015: A systematic analysis for the Global Burden of Disease Study 2015. Lancet Neurol 16, 877-897.

[3] Bach J-P, Ziegler U, Deuschl G, Dodel R, DoblhammerReiter G (2011) Projected numbers of people with movement disorders in the years 2030 and 2050. Mov Disord 26, 2286-2290.

[4] Dorsey ER, Bloem BR (2018) The Parkinson pandemic-a call to action. JAMA Neurol 75, 9 .

[5] Sakushima K, Yamazaki S, Fukuma S, Hayashino Y, Yabe I, Fukuhara S, Sasaki H (2016) Influence of urinary urgency and other urinary disturbances on falls in Parkinson's disease. J Neurol Sci 360, 153-157.

[6] van der Kolk NM, King LA (2013) Effects of exercise on mobility in people with Parkinson's disease. Mov Disord 28, 1587-1596.

[7] Chaudhuri KR, Healy DG, Schapira AH (2006) Non-motor symptoms of Parkinson's disease: Diagnosis and management. Lancet Neurol 5, 235-245.

[8] Soh S-E, Morris ME, McGinley JL (2011) Determinants of health-related quality of life in Parkinson's disease: A systematic review. Parkinsonism Relat Disord 17, 1-9.

[9] Nutt JG, Bloem BR, Giladi N, Hallett M, Horak FB, Nieuwboer A (2011) Freezing of gait: Moving forward on a mysterious clinical phenomenon. Lancet Neurol 10, 734744.

[10] Moore O, Peretz C, Giladi N (2007) Freezing of gait affects quality of life of peoples with Parkinson's disease beyond its relationships with mobility and gait. Mov Disord 22, 21922195.

[11] Macht M, Kaussner Y, Möller JC, Stiasny-Kolster K, Eggert KM, Krüger H-P, Ellgring H (2007) Predictors of freezing in Parkinson's disease: A survey of 6,620 patients. Mov Disord 22, 953-956.

[12] Vitório R, Lirani-Silva E, Barbieri FA, Raile V, Stella F, Gobbi LTB (2013) Influence of visual feedback sampling on obstacle crossing behavior in people with Parkinson's disease. Gait Posture 38, 330-334.

[13] Galna B, Murphy AT, Morris ME (2013) Obstacle crossing in Parkinson's disease: Mediolateral sway of the centre of mass during level-ground walking and obstacle crossing. Gait Posture 38, 790-794.

[14] Nocera JR, Horvat M, Ray CT (2010) Impaired step up/over in persons with Parkinson's disease. Adapt Phys Act Q 27, 87-95. 
[15] Davidsdottir S, Cronin-Golomb A, Lee A (2005) Visual and spatial symptoms in Parkinson's disease. Vision Res 45, 1285-1296.

[16] Rahman S, Griffin HJ, Quinn NP, Jahanshahi M (2008) The factors that induce or overcome freezing of gait in Parkinson's disease. Behav Neurol 19, 127-136.

[17] Braun D, Barnhardt K (2014) Critical thinking. Crit Care Nurs Q 37, 33-40.

[18] Day K, Carreon D, Stump C (2000) The therapeutic design of environments for people with dementia. Gerontologist 40, 397-416.

[19] Innes A, Kelly F, Dincarslan O (2011) Care home design for people with dementia: What do people with dementia and their family carers value? Aging Ment Health 15, 548-556.

[20] Büter K, Motzek T, Dietz B, Hofrichter L, Junge M, Kopf D, von Lützau-Hohlbein H, Traxler S, Zieschang T, Marquardt G (2017) Demenzsensible Krankenhausstationen. $Z$ Gerontol Geriatr 50, 67-72.

[21] Marquardt G, Schmieg P (2009) Demenzfreundliche Architektur. Z Gerontol Geriatr 42, 402-407.

[22] Mooney P, Nicell PL (1992) The importance of exterior environment for Alzheimer residents: Effective care and risk management. Healthc Manag Forum 5, 23-29.

[23] Marquardt G (2011) Wayfinding for people with dementia: A review of the role of architectural design. Herd/Health Environ Res Des J 4, 75-90.

[24] Calkins MP (2009) Evidence-based long term care design. Neurorehabilitation 25, 145-154.

[25] Marquardt G, Bueter K, Motzek T (2014) Impact of the design of the built environment on people with dementia: An evidence-based review. HERD 8, 127-157.

[26] Reid D (2004) Accessibility and usability of the physical housing environment of seniors with stroke. Int J Rehabil Res 27, 203-208.

[27] Jellema S, van der Sande R, van Hees S, Zajec J, Steultjens EM, Nijhuis-van der Sanden MW (2016) Role of environmental factors on resuming valued activities poststroke: A systematic review of qualitative and quantitative findings. Arch Phys Med Rehabil 97, 991-1002.e1.

[28] Nijkrake MJ, Keus SHJ, Oostendorp RAB, Overeem S, Mulleners W, Bloem BR, Munneke M (2009) Allied health care in Parkinson's disease: Referral, consultation, and professional expertise. Mov Disord 24, 282-286.

[29] Bhidayasiri R, Jitkritsadakul O, Boonrod N, Sringean J, Calne SM, Hattori N, Hayashi A (2015) What is the evidence to support home environmental adaptation in Parkinson's disease? A call for multidisciplinary interventions. Parkinsonism Relat Disord 21, 1127-1132.

[30] Stack E, Ashburn A (1999) Fall events described by people with Parkinson's disease: Implications for clinical interviewing and the research agenda. Physiother Res Int 4, 190-200.

[31] Gray P, Hildebrand K (2000) Fall risk factors in Parkinson's disease. J Neurosci Nurs 32, 222-228.

[32] Ashburn A, Stack E, Ballinger C, Fazakarley L, Fitton C (2008) The circumstances of falls among people with Parkinson's disease and the use of Falls Diaries to facilitate reporting. Disabil Rehabil 30, 1205-1212.

[33] Cole MH, Silburn PA, Wood JM, Kerr GK (2011) Falls in Parkinson's disease: Evidence for altered stepping strategies on compliant surfaces. Parkinsonism Relat Disord 17, 610616.

[34] Stack EL, Roberts HC (2013) Slow down and concentrate: Time for a paradigm shift in fall prevention among people with Parkinson's disease? Parkinsons Dis 2013, 704237.
[35] Gazibara T, Pekmezovic T, Tepavcevic DK, Tomic A, Stankovic I, Kostic VS, Svetel M (2014) Circumstances of falls and fall-related injuries among patients with Parkinson's disease in an outpatient setting. Geriatr Nurs 35, 364-369.

[36] Gazibara T, Kisic-Tepavcevic D, Svetel M, Tomic A, Stankovic I, Kostic VS, Pekmezovic T (2016) Indoor and outdoor falls in persons with Parkinson's disease after 1 year follow-up study: Differences and consequences. Neurol Sci 37, 597-602.

[37] Jones D, Rochester L, Birleson A, Hetherington V, Nieuwboer A, Willems AM, Van Wegen E, Kwakkel G (2008) Everyday walking with Parkinson's disease: Understanding personal challenges and strategies. Disabil Rehabil 30, 1213-1221.

[38] Rahman S, Griffin HJ, Quinn NP, Jahanshahi M (2011) On the nature of fear of falling in Parkinson's disease. Behav Neurol 24, 219-228.

[39] Nilsson MH, Hariz GM, Iwarsson S, Hagell P (2012) Walking ability is a major contributor to fear of falling in people with Parkinson's disease: Implications for rehabilitation. Parkinsons Dis 2012, 713236.

[40] Jonasson SB, Ullén S, Iwarsson S, Lexell J, Nilsson MH (2015) Concerns about falling in Parkinson's disease: Associations with disabilities and personal and environmental factors. J Parkinsons Dis 5, 341-349.

[41] Giladi N, McMahon D, Przedborski S, Flaster E, Guillory S, Kostic V, Fahn S (1992) Motor blocks in Parkinson's disease. Neurology 42, 333-333.

[42] Lee A, Harris J (1999) Problems with perception of space in Parkinson's disease: A questionnaire study. Neuroophthalmology 22, 1-15.

[43] Nieuwboer A, Dom R, De Weerdt W, Desloovere K, Fieuws S, Broens-Kaucsik E (2001) Abnormalities of the spatiotemporal characteristics of gait at the onset of freezing in Parkinson's disease. Mov Disord 16, 1066-1075.

[44] Schaafsma JD, Balash Y, Gurevich T, Bartels AL, Hausdorff JM, Giladi N (2003) Characterization of freezing of gait subtypes and the response of each to levodopa in Parkinson's disease. Eur J Neurol 10, 391-398.

[45] Nieuwboer A, Dom R, De Weerdt W, Desloovere K, Janssens L, Stijn V (2004) Electromyographic profiles of gait prior to onset of freezing episodes in patients with Parkinson's disease. Brain 127, 1650-1660.

[46] Almeida QJ, Lebold CA (2010) Freezing of gait in Parkinson's disease: A perceptual cause for a motor impairment? J Neurol Neurosurg Psychiatry 81, 513-518.

[47] Cowie D, Limousin P, Peters A, Day BL (2010) Insights into the neural control of locomotion from walking through doorways in Parkinson's disease. Neuropsychologia 48, 2750-2757.

[48] Lebold CA, Almeida QJ (2010) Evaluating the contributions of dynamic flow to freezing of gait in Parkinson's disease. Parkinsons Dis 2010, 732508.

[49] Cowie D, Limousin P, Peters A, Hariz M, Day BL (2011) Doorway-provoked freezing of gait in Parkinson's disease. Mov Disord 27, 492-499.

[50] Kataoka H, Tanaka N, Eng M, Saeki K, Kiriyama T, Eura N, Ikeda M, Izumi T, Kitauti T, Furiya Y, Sugie K, Ikada Y, Ueno S (2011) Risk of falling in Parkinson's disease at the Hoehn-Yahr stage III. Eur Neurol 66, 298-304.

[51] Stegemoller EL, Buckley TA, Pitsikoulis C, Barthelemy E, Roemmich R, Hass CJ (2012) Postural instability and gait impairment during obstacle crossing in Parkinson's disease. Arch Phys Med Rehabil 93, 703-709. 
[52] Oates AR, Van Ooteghem K, Frank JS, Patla AE, Horak FB (2013) Adaptation of gait termination on a slippery surface in Parkinson's disease. Gait Posture 37, 516-520.

[53] Mak MKY, Yu L, Hui-Chan CWY (2013) The immediate effect of a novel audio-visual cueing strategy (simulated traffic lights) on dual-task walking in people with Parkinson's disease. Eur J Phys Rehabil Med 49, 153-159.

[54] Kataoka H, Tanaka N, Kiriyama T, Eura N, Horikawa H, Ikada Y, Ueno S (2012) Paradoxical gait at a narrowed entrance in a patient with Hoehn-Yahr Stage III Parkinson's disease. Eur Neurol 68, 276-278.

[55] Kataoka H, Tanaka N, Kiriyama T, Eura N, Ikeda M, Izumi T, Furiya Y, Sugie K, Ueno S (2018) Step numbers and Hoehn-Yahr Stage after six years. Eur Neurol 79, 118-124.

[56] Ehgoetz Martens KA, Pieruccini-Faria F, Almeida QJ (2013) Could sensory mechanisms be a core factor that underlies freezing of gait in Parkinson's disease? PLoS One 8, e62602.

[57] Almeida QJ, Frank JS, Roy EA, Jenkins ME, Spaulding S, Patla AE, Jog MS (2005) An evaluation of sensorimotor integration during locomotion toward a target in Parkinson's disease. Neuroscience 134, 283-293.

[58] Gál O, Poláková K, Hoskovcová M, Tomandl J, Čapek V, Berka R, Brožová H, Šestáková I, Růžička E (2019) Pavement patterns can be designed to improve gait in Parkinson's disease patients. Mov Disord 34, 1831-1838.

[59] Pretzer-Aboff I, Galik E, Resnick B (2009) Parkinson's disease: Barriers and facilitators to optimizing function. Rehabil Nurs 34, 54-60.

[60] Lamont RM, Morris ME, Woollacott MH, Brauer SG (2012) Community walking in people with Parkinson's disease. Parkinsons Dis 2012, 856237.

[61] Nilsson MH, Haak M, Iwarsson S (2013) Housing and health: Very old people with self-reported Parkinson's disease versus controls. Parkinsons Dis 2013, 710839.

[62] Slaug B, Nilsson MH, Iwarsson S (2013) Characteristics of the personal and environmental components of personenvironment fit in very old age: A comparison between people with self-reported Parkinson's disease and matched controls. Aging Clin Exp Res 25, 667-675.

[63] Haak M, Slaug B, Löfqvist C, Nilsson MH (2013) Technical aids and housing adaptations among very old people with self-reported Parkinson's disease compared to matched controls. Res Rev Parkinsonism 3, 41-47.

[64] Snijders AH, Jeene P, Nijkrake MJ, Abdo WF, Bloem BR (2012) Cueing for freezing of gait: A need for 3-dimensional cues? Neurologist 18, 404-405.

[65] Janssen S, Soneji M, Nonnekes J, Bloem BR (2016) A painted staircase illusion to alleviate freezing of gait in Parkinson's disease. J Neurol 263, 1661-1662.

[66] Gilat M, Hall JM, Ehgoetz Martens KA, Shine JM, Walton CC, MacDougall HG, Moore ST, Lewis SJG (2017) Staircase climbing is not solely a visual compensation strategy to alleviate freezing of gait in Parkinson's disease. J Neurol 264, 174-176.

[67] Aragon A, Kings J (2010) Occupational therapy for people with Parkinson's. Parkinson's UK and College of Occupational Therapists, London.

[68] Griffin HJ, Greenlaw R, Limousin P, Bhatia K, Quinn NP, Jahanshahi M (2011) The effect of real and virtual visual cues on walking in Parkinson's disease. J Neurol 258, 9911000.

[69] Lebold CA, Almeida QJ (2011) An evaluation of mechanisms underlying the influence of step cues on gait in Parkinson's disease. J Clin Neurosci 18, 798-802.
[70] Spildooren J, Vercruysse S, Meyns P, Vandenbossche J, Heremans E, Desloovere K, Vandenberghe W, Nieuwboer A (2012) Turning and unilateral cueing in Parkinson's disease patients with and without freezing of gait. Neuroscience 207, 298-306.

[71] Muthukrishnan N, Abbas JJ, Shill HA, Krishnamurthi N (2019) Cueing paradigms to improve gait and posture in Parkinson's disease: A narrative review. Sensors (Switzerland) 19, 1-16.

[72] Keus S, Munneke M, Graziano M, Paltamaa J, Pelosin E, Domingos J, Brühlmann S (2014) European Physiotherapy Guideline for Parkinson's Disease. KNGF/ParkinsonNet, the Netherlands, pp. 1-191.

[73] Sweeney D, Quinlan LR, Browne P, Richardson M, Meskell P, Ólaighin G (2019) A technological review of wearable cueing devices addressing freezing of gait in Parkinson's disease. Sensors (Basel) 19, 1277.

[74] Nieuwboer A, Kwakkel G, Rochester L, Jones D, van Wegen E, Willems AM, Chavret F, Hetherington V, Baker K, Lim I (2007) Cueing training in the home improves gait-related mobility in Parkinson's disease: The RESCUE trial. $\mathrm{J} \mathrm{Neu}$ rol Neurosurg Psychiatry 78, 134-140.

[75] Nieuwboer A (2008) Cueing for freezing of gait in patients with Parkinson's disease: A rehabilitation perspective. Mov. Disord. 23 (Suppl 2), S475-S481.

[76] Sturkenboom IHWM, Thijssen MCE, Gons-van Elsacker JJ, Jansen IJH, Maasdam A, Schulten M, Vijver-Visser D, Steultjens EJM, Bloem BR, Munneke M (2011) Guidelines for Occupational Therapy in Parkinson's Disease Rehabilitation. ParkinsonNet/NPF, Nijmegen, The Netherlands/Miami (FL), USA.

[77] Ekker MS, Janssen S, Seppi K, Poewe W, de Vries NM, Theelen T, Nonnekes J, Bloem BR (2017) Ocular and visual disorders in Parkinson's disease: Common but frequently overlooked. Parkinsonism Relat Disord 40, 1-10.

[78] Borm CDJM, Visser F, Werkmann M, de Graaf D, Putz D, Seppi K, Poewe W, Vlaar AMM, Hoyng C, Bloem BR, Theelen T, de Vries NM (2020) Seeing ophthalmologic problems in Parkinson disease. Neurology 94, e1539-e1547.

[79] Borm CDJM, Smilowska K, de Vries NM, Bloem BR, Theelen $T$ (2019) The neuro-ophthalmological assessment in Parkinson's disease. J Parkinsons Dis 9, 427-435.

[80] Jacobs JV (2016) A review of stairway falls and stair negotiation: Lessons learned and future needs to reduce injury. Gait Posture 49, 159-167.

[81] Skinner JW, Lee HK, Roemmich RT, Amano S, Hass CJ (2015) Execution of activities of daily living in persons with Parkinson disease. Med Sci Sport Exerc 47, 1906-1912.

[82] Dusenberry DO, Simpson H, DelloRusso SJ (2009) Effect of handrail shape on graspability. Appl Ergon 40, 657-669.

[83] Lee S, Lee C, Rodiek S (2017) Neighborhood factors and fall-related injuries among older adults seen by emergency medical service providers. Int J Environ Res Public Health 14, 163.

[84] Wall RS, Ashmead DH, Bentzen BL, Barlow J (2004) Directional guidance from audible pedestrian signals for street crossing. Ergonomics 47, 1318-1338.

[85] Yen IH, Fandel Flood J, Thompson H, Anderson LA, Wong G (2014) How design of places promotes or inhibits mobility of older adults. J Aging Health 26, 1340-1372.

[86] Granbom M, Iwarsson S, Kylberg M, Pettersson C, Slaug B (2016) A public health perspective to environmental bar- 
riers and accessibility problems for senior citizens living in ordinary housing. BMC Public Health 16, 772.

[87] Zandieh R, Martinez J, Flacke J, Jones P, van Maarseveen M (2016) Older adults' outdoor walking: Inequalities in neighbourhood safety, pedestrian infrastructure and aesthetics. Int J Environ Res Public Health 13, 1179.
[88] Liberati A, Altman DG, Tetzlaff J, Mulrow C, Gotzsche PC, Ioannidis JPA, Clarke M, Devereaux PJ, Kleijnen J, Moher D (2009) The PRISMA statement for reporting systematic reviews and meta-analyses of studies that evaluate healthcare interventions: Explanation and elaboration. BMJ 339, b2700. 